Raf. J. Sci.,Vol.28, No.2 Special Issue for the Third Scientific Conference of Chemistry, pp.211-227, 2019

\title{
Studies on Preparation and Characterization of Blend Polymers for Hydrogels Synthesis and Use for Protein Release
}

\author{
Roua'a K. Al-Ojar \\ Ministry of Science and Technology
}

\author{
Fawzi H. Jabrail \\ Department of Chemistry/ College of Sciencel \\ University of Mosul
}

(Received 30/9/2018 ; Accepted 25/10/5018)

\begin{abstract}
Carboxy methyl cellulose, pectin, chitosan or acrylic acid- poly (vinyl alcohol) blend hydrogels were prepared using Glutaraldehyde (GLU) as chemical or sodium hexameta phosphate (SHMP) as physical cross-linking agent. The prepared hydrogels have carried the advantage properties of both blend materials and can be used for loading and releasing of BSA protein. The degree of swelling of the prepared hydrogels was measured due to their different functional groups in different $\mathrm{pHs}$ of $(\mathrm{pH} 4, \mathrm{pH} 7$ and $\mathrm{pH} 9)$ in addition to the electrolyte solution of $0.1 \mathrm{~N} \mathrm{NaCl}$. The blend hydrogels are characterized for their chemical structure using FT-IR. The XRD analysis was investigated for determination of the hydrogels crystallographic structure. The differential thermal analysis DTA and scanning electron microscope SEM were depended to study the thermal stability and surface morphology of the hydrogel respectively. The hydrogels were loaded with BSA protein model, and time of loading at $(1.5,3.0,4.5$ and 6.0) hrs were measured, beside the $\mathrm{pH}$ of the loading solution of $\mathrm{ph} 4, \mathrm{pH} 6$ and $\mathrm{pH} 8$ were considered and the BSA concentrations of $(0.5,1.0,1.5$ and 2.0) $\mathrm{g} / \mathrm{L}$ have been investigated for maximum loading percentages $\% \mathrm{~L}_{\max }$ of $\mathrm{BSA}$ on the hydrogels. Finally the loaded BSA was released under different release conditions in $0.9 \% w / v \mathrm{NaCl}$ solution and $\mathrm{pH} 4, \mathrm{pH} 6$ and $\mathrm{pH} 8$ were depended and the BSA was tested to release at 15, 25 and $40^{\circ} \mathrm{C}$ releasing medium temperatures.
\end{abstract}

Keywords: Poly (vinyl alcohol) hydrogel; Bovine serum albumin release; Natural occurring polymers; Chitosan; Pectin; Carboxy methyl cellulose; Acrylic acid.

\section{درلسة حطل تحضير وتشخيص هيدوجيلات من توليف البوليمرل ولستخدامهاف إلالاق البروتن}

\section{المالغص}

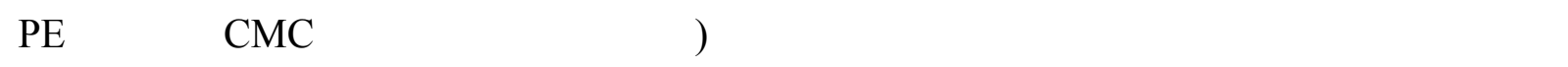

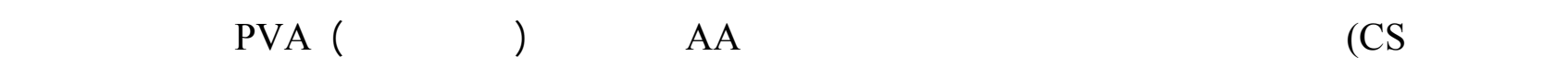
التثابك الكيميأي الكلوتارالديهايد GLU او علمل التشابك الفيزيائي الهكسلميتا فوسفلت الصوديوم SHMP.

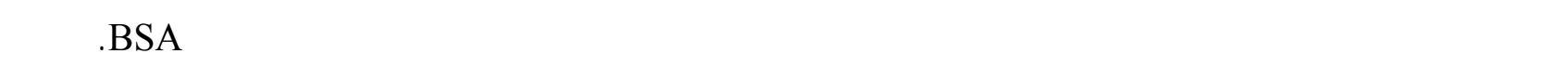

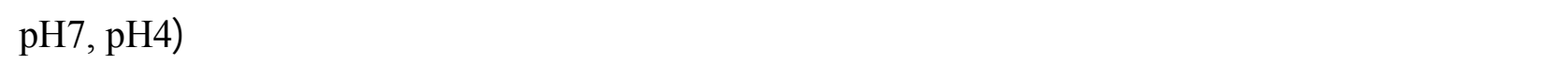

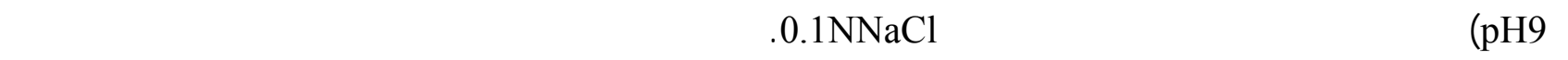
بالاعتماد على مطيف الأشعة تهت الحمراء FTIR، كما وم درلسة تحليل XRD لقدير الترلكيب البلورية للهيدروجل. وقد اعتمد جهاز التحليل الحراري الفاضلي DTA وجهاز المسح المجهري الألكترويف SEM لِدرلاهية الإسِقراريةِ الحرارية وبنية للسطح (المورفولوجيا) للهيدروجيل على التوالي. لدرلسة تحمل الهيدروجيل مت اعتماد بروتين BSA كمويل للتحميل، قيلس

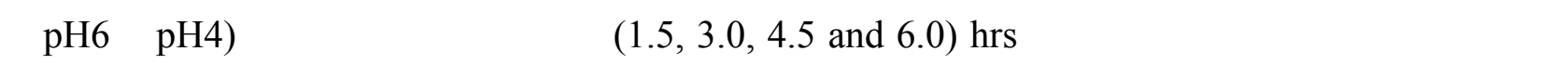


(pH8 أمحلول التحمل وكذك تركيزمحلول BSA عند g/LA (0.5, 1.0, 1.5 and 2.0)، وذك للحصول على نسب التحمل

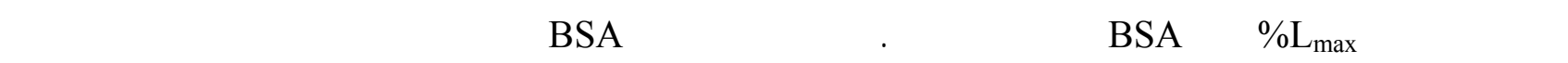

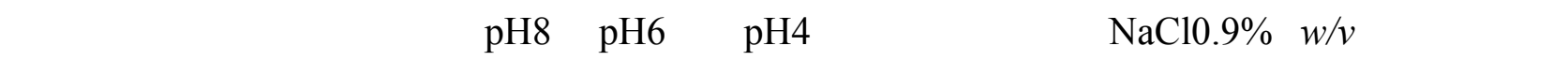
.$(15,25 \text { and } 40)^{\circ} \mathrm{C}$

$$
\begin{aligned}
& \text { الكاملت الدالة: هيدروجيلالبولي فيناليل الكحول؛ لطلاق ألبومين مصل الدم القري؛ بوليمرات طبيعية؛ كايتوسان؛ بكتين؛ } \\
& \text { كاربوكسي مثلسسليلوز؛ حلمض الكريلك. }
\end{aligned}
$$

INTRODUCTION

Hydrogels are polymers have the ability to imbibing hugeamount of water or any bio-fluids due to their dimension structure and the presence of a lot of hydrolysable groups (Mallikarjuna et al., 2014; Maitra and Shukla, 2014). Hydrogels are cross-linked chemically or through physical interactions (Ahmed, 2015); the interaction occurs between polymer and liquid as water is called polymer- liquid interaction and if the polymer is hydrophilic in its nature at that the product is called hydrosol (McKenzie et al., 2015) which depend on many elements present in the polymer's structure or in the solution, such as functional groups of the polymer beside the ions present in the polymer structure, their types and amounts, in addition to the $\mathrm{pH}$ and temperature of the polymer solution (Ghobashy et al., 2017). The chemical cross-linked hydrogel are permanent and hardly dissociated, whereas physical cross-linked hydrogel and because are formed by secondary forces like hydrogen bonding or ionic interactions and recent are reversible and may disrupted through the change in physical forces or under stress (Kitsara and Ducr'ee, 2013).

Poly(vinyl alcohol) PVA is hydrophilic and semi- crystalline polymer, it is linear and easily soluble in water (Gomez et al., 2017). PVA has ability to blend with synthetic and natural monomers or polymers (Marin, et al., 2014). The formed hydrogels of PVA are biomaterials have desirable properties and could improve their thermal, mechanical, physical and chemical properties. The blend hydrogels of the final improvement properties are depended fundamentally on the embedded materials properties (Marin et al., 2014). Natural occurring polymers with their convenient properties like compatibility, high hydrophilicity, biodegradability and low production cost are very important materials to share synthetic polymers in preparation of superabsorbent polymer (Pourjavadi et al., 2010). Carboxy methyl cellulose CMC, the important cellulose derivatives, is a linear, long chain with anionic water soluble polysaccharide material (Gupta and Jabrial, 2007). Whereas chitosan CS, the cationic amino polysaccharide, which produced from chitin is biocompatible, non-toxic and insoluble in water and organic solvent. although it is a hydrophilic polymer, its dissolution in water only takes place in dilute acidic solution like acetic acid (Mallakpour and Ezhieh, 2017; Del Valle et al., 2017; Fan et al., 2016).

Pectin is a natural biopolymer has a hetero structure polysaccharide mainly extracted from citrus fruits and used as a gelling agents, thickening agent and stabilizer and have several applications (Mongkolkitikul et al., 2018).

In the present work, hydrogels are prepared from blending of carboxymethylcellulose (CMC), pectin (PE), and chitosan (CS), as a natural occurring polymers and acrylic acid (AA) as a synthetic monomer with poly (vinyl alcohol) (PVA). The prepared hydrogels were cross-linked for comparison chemically and physically usingGlutaraldehyde and sodium hexameta phosphate (SHMP) respectively. The cross-linked hydrogels were used after loading for releasing of bovine serum albumin (BSA) protein in physiological saline (PS) solution.

\section{Materials}

\section{EXPERIMENTAL}

Poly (vinyl alcohol) (PVA: average mol. Wt. (MW) 101,000 g.mol ${ }^{-1}$ ) was obtained from Qualiquens, India. Pectin (PE: MW:20,000 g. $\mathrm{mol}^{-1}$ ), Carboxy methyl cellulose (CMC: MW:250,000 
g.mol $l^{-1}$ ), Chitosan (CS: MW:200,000 g.mol ${ }^{-1}$ ) were obtained from BDH, UK; Fluka, SW; SigmaAldrich, UK, respectively. Acrylic acid (AA) was obtained from CAS, India. The cross-linkers Glutaraldehyde (GLU: 50 wt $\%$ ) and Sodium hexameta phosphate SHMP were obtained from Fluka, SW and BDH, UK respectively. bovine serum albumin (BSA) was obtained from Fluka, SW. Preparation of PVA Blend Hydrogels

$10 \mathrm{ml}$ of $10 \% \mathrm{w} / \mathrm{v}$ PVA aqueous solutionwere prepared separately in different beakers. In other beakers, solution of $5 \mathrm{ml}$ of $25 \% \mathrm{w} / \mathrm{v}$ of CMC in aqueous solution, $10 \mathrm{ml}$ of $2 \% \mathrm{w} / \mathrm{v}$ of PE in aqueous solution, $5 \mathrm{ml}$ of $20 \% \mathrm{w} / \mathrm{v}$ in $5 \% \mathrm{v} / \mathrm{v}$ of CS in acetic acid solution and $8 \mathrm{ml}$ of $85 \% \mathrm{w} / \mathrm{v}$ of AA in $30 \% w / v \mathrm{NaOH}$ alkaline solution were prepared. All previous solutions were prepared in equimoles with PVA solution according to their average molecular weights. Where $10^{-3} \mathrm{M}$ of natural polymer solution or synthetic monomer, has been added into PVA solution (Wang and Gunasekaran, 2006) $10 \mathrm{ml}$ of $5 \% \mathrm{w} / \mathrm{v}$ of the initiator ammonium persulfate APS was added, then the final collected solutions were divided into two portions before the addition of cross-linker.

Subsequently, for preparation of natural polymer (CMC, PE and CS) blend PVA hydrogel, $5 \mathrm{ml}$ of $30 \% \mathrm{w} / \mathrm{v}$ aqueous solution of SHMP as physical cross-linker was added for one portion and $0.5 \mathrm{ml}$ of $50 \mathrm{wt} \% \mathrm{GLU}$ as chemical cross-linker was added for the second portion.

Quick addition with vigorous mixing of the cross-linkers has been done in order to avoid fast agglomeration and un-homogenized products. The blend content was continued mixing for extra one hour and finally, the beakers were left in the oven less than $60 \mathrm{C}^{\circ}$ until dried.

Similarly, the preparation of AA blend PVA hydrogel was prepared with same procedure only the difference is in the amounts of cross-linker added, where $3.5 \mathrm{ml}$ of $10 \% \mathrm{w} / \mathrm{v}$ aqueous solution of SHMP or $0.25 \mathrm{ml}$ of $50 \mathrm{wt} \%$ GLU were added.

\section{Characterizations of the hydrogels FT-IR Spectroscopy}

Fourier Transformer Infrared spectrophotometer type Shimazdu IR- Affinity/ Japan instrument was used for characterization of the prepared hydrogels. Where the wavenumbers of the hydrogel characterization bands are recorded in Table 1 for hydrogels cross-linked chemically and Table 2 for hydrogels cross-linked physically and after the hydrogels are loaded with the BSA model protein.

\section{X-ray diffraction}

X-ray diffraction type XRD-P analytical, 2013, Netherland, was used for characterization of the crystal structure of the pristine hydrogels were recorded up to 20 scale in an angle range of $5^{\circ}$ $90^{\circ}$ at a scan speed of $1 \%$ min using copper/Indium (0.9/0.1) $100 \%$ radiation target and nickel filter at a current of around $20 \mu \mathrm{A}$ a voltage of $35 \mathrm{kv}$.

The crystallinity percentage $\left(\% \mathrm{X}_{\mathrm{c}}\right)$ was calculated according to:

$$
\% X_{c}=\frac{A c}{A a+A c \times} \mathbf{1 0 0}
$$

Where, $A_{c}$ and $A_{a}$ are the area of crystalline and amorphous phases, respectively.

\section{Thermal analysis}

Differential thermal analysis DTA, beside maximum temperature decomposition $T_{\max }$ and glass transition temperature $\mathrm{T}_{\mathrm{g}}$ of the BSA loaded and unloaded hydrogels were investigated using Thermal analysis, DTA-60/ Simultaneous DTA-TG, Apparatus, Shimazdu/ Japan instrument, with heating rate of $10^{\circ} \mathrm{C} / \mathrm{min}$ in nitrogen atmosphere.

\section{SEM analysis}

The SEM micrographs of pristine, BSA loaded and after release hydrogels were studied, and TESCAN, Vega, III, 2011, Czech Republic instrument was used. Where double adhesive taps have been fixed on aluminum studs and the samples were mounted on it and then coated with cold ion under vacuum using beam sputter.

\section{Degree of swelling measurements}

The degree of swelling $\left(\mathrm{S}_{\mathrm{w}}\right)$ of prepared hydrogels weremeasured after cut off the hydrogel into $1-3 \mathrm{~mm}$ size pieces. Fixed weight of dry hydrogel pieces were immersed in distilled water and 
their precise weight each 3 hrs has been measured after removal of all un-adsorbed water drops, even tissue paper were used for more accuracy. The following equation was depended for $S_{w}$ measuring (Sing et al., 2008).

$$
S_{W} \%=\frac{W_{t}-W_{q}}{W_{u}} \times 100
$$

Where, $\mathrm{W}_{\mathrm{t}}$ is the weight of swell hydrogel at time $\mathrm{t}$, and $\mathrm{W}_{\mathrm{o}}$ is the weight of dry hydrogel. The effects of the $\mathrm{pH}$ swelling medium were investigated in acidic, neutral and basic medium of $\mathrm{pH} 4$, pH6 and pH8, respectively.

\section{Loading of hydrogels with BSA Protein}

Three loading effective variables were studied on BSA loading hydrogels are time, $\mathrm{pH}$ of loading medium and the concentration of BSA protein used for loading. $100 \mathrm{mg}$ of the hydrogels were immersed in beaker contain $50 \mathrm{ml}$ of $2.0 \mathrm{~g} / \mathrm{L}$ BSA concentration and the maximum loading was examined in $\mathrm{pH} 4, \mathrm{pH} 6$ and $\mathrm{pH} 8$ for $12 \mathrm{hrs}$ at room temperature. Each $1.5 \mathrm{hrs}$ the hydrogel pieces were removed and the remain BSA solution was measured using UV-visible spectrophotometer Jasco V-630 spectrophotometer/ Japan, where the instrument was fixed at $\lambda_{\max } 279 \mathrm{~nm}$ and the absorbance (A) was measured and calibration curve was used for determination of remain BSA solution concentration. However, the favorable loading $\mathrm{pH}$ solution was fixed and the time of loading also measured at $(1.5,3.0,4.5$ and 6.0$) \mathrm{hrs}$ beside the BSA loading concentrations was changed between $(0.5,1.0,1.5$ and 2.0$) \mathrm{g} / \mathrm{L}$ for optimum loading conditions. The following equations were applied for determination of maximum loading $\left(\mathrm{L}_{\max }\right)$ and efficiency of loading (EL) of the hydrogels (Krishna et al., 2008).

$$
\begin{array}{ll}
\% \mathbf{L}_{\max }=\frac{\text { Amount of BSA protien loaded on hydrogel }}{\text { Amount of hydrogel taken for loading }} & \times 100 \\
\% \mathbf{E L}=\frac{\text { Amount of BSA protien loaded on hydrogel }}{\text { Amount of BSA protien taken for loading }} & \times 100
\end{array}
$$

\section{Cumulative release of BSA protein from hydogel}

$100 \mathrm{mg}$ of BSA maximum loaded hydrogels were kept in $200 \mathrm{ml}$ of physiological saline PS solution prepared from $0.9 \% \mathrm{w} / v$ aqueous solution of $\mathrm{NaCl}$. The cumulative release of BSA from the hydrogels was measured each $3 \mathrm{hrs}$ and for time intervals of $12 \mathrm{hrs}$ by recording the absorbance A at $\lambda_{\max } 279 \mathrm{~nm}$ of release medium and with replacement using UV-Visible spectrophotometer. The cumulative release $\left(\mathrm{R}_{\text {cum }}\right)$ of BSA protein was calculated by the following equation (Saputra et al., 2014).

$$
\text { Cumulative release }\left(\% \mathbf{R}_{\text {cum }}\right)=\frac{W_{t}}{W_{v}} \times 100
$$

Where, $W_{t}$ is the amount of BSA protein released at time $\mathrm{t}$, and $W_{o}$ is represent total amount of BSA protein release finally.

Two variables are considered for measuring $\mathrm{R}_{\text {cum }}$ are temperature of the release medium and its $\mathrm{pH}$ as $\mathrm{pH} 4, \mathrm{pH} 6$ and $\mathrm{pH} 8$ were tested for calculation of $\mathrm{R}_{\text {cum. }}$.

\section{RESULTS AND DISCUSSION}

Prepared hydrogel by blending are usually retain the unique properties of their individual components, and finally hydrogels are combination of two or more different and unusual properties in one polymer structure.

Smart or intelligent polymers that are responsive to external stimuli such as temperature, $\mathrm{pH}$ for applications in bioseparation and bioprocessing of biomaterials like protein. 


\section{Hydrogels Characterization}

Poly (vinyl alcohol) PVA was used for preparation of blend hydrogels and the following abbreviationcodes were depended:

1- CMC blend PVA and cross-linked chemically is CMC/ P-b-CH

2- CMC blend PVA and cross-linked physically is $\mathbf{C M C / ~ P - b - P H}$

3- PE blend PVA and cross-linked chemically is $\mathbf{P E} / \mathbf{P}-\mathbf{b}-\mathbf{C H}$

4- PE blend PVA and cross-linked physically isPE/ P-b-PH

5- CS blend PVA and cross-linked chemically is $\mathbf{C S} / \mathbf{P}-\mathbf{b}-\mathbf{C H}$

6- CS blend PVA and cross-linked physically is CS/ P-b-PH

7- AA blend PVA and cross-linked chemically is AA/ P-b-CH

8- AA blend PVA and cross-linked physically is AA/ P-b-PH

The pristine hydrogels are characterized depending on their FT-IR, X-ray diffraction, thermal and SEM analysis.

\section{FT-IR Spectroscopy}

FT-IR spectra of the hydrogels were measured and the absorption frequencies of their features functional groups were studies for fixing the hydrogel chemical composition, nature of bonding and the type of the conjugations.

The important characteristic bands of the investigated hydrogels are almost same especially for the same hydrogel and the only differences are the type of cross-linker, Where either acetyl linkages formed by Glutaraldehyde cross-linker or phosphate linkages formed by SHMP crosslinker. The characteristic bands of hydroxyl group $\gamma(\mathrm{O}-\mathrm{H})$ of PVA beside the methyl carboxylate anions in $\mathrm{CMC}$ polymer occurred in $\mathrm{CMC} / \mathrm{P}-\mathrm{b}-\mathrm{CH}$ and $\mathrm{CMC} / \mathrm{P}-\mathrm{b}-\mathrm{PH}$ hydrogels Fig.(1) and Tables (1 and 2) have absorption frequencies almost same and only the frequencies appear at $(722,1150$, 1100 and 1280) $\mathrm{cm}^{-1}$ which represent the $\gamma(\mathrm{P}-\mathrm{O}-\mathrm{P})_{\text {str }}$ band of SHMP (Saputra et al., 2014).

Table 1: FT-IR Wavenumbers of the characteristic bands of chemical cross-linked hydrogels

\begin{tabular}{|c|c|c|c|c|c|c|c|c|}
\hline \multirow{2}{*}{$\begin{array}{c}\text { Examined } \\
\text { Sample }\end{array}$} & \multicolumn{7}{|c|}{ Wavenumber of characteristic band, cm } \\
\cline { 2 - 9 } & $y(\mathrm{O}-\mathrm{H}) \mathrm{str}$ & $\gamma(\mathrm{C}-\mathrm{H}) \mathrm{str}$ & $\gamma(\mathrm{C}=\mathrm{O})$ str & $\gamma(\mathrm{C}-\mathrm{O}) \mathrm{str}$ & $\gamma(\mathrm{C}-\mathrm{O}-\mathrm{C}) \mathrm{str}$ & $\gamma(\mathrm{N}-\mathrm{H}) \mathrm{str}$ & $y(\mathrm{C}-\mathrm{N}) \mathrm{str}$ & $y(\mathrm{C}-\mathrm{H}) \mathrm{def}$ \\
\hline CMC/P-b-CH & 3493,1340 & 2950 & 1620,1738 & 1440 & 1150 & ------ & ------ & 781,802 \\
\hline PE/P-b-CH & 3435,1320 & ---- & 1650,1390 & 1450 & 1150 & ------ & ------ & 760,804 \\
\hline CS/P-b- CH & 3470,1320 & 2860 & 1744 & 1075 & 1146 & 3210 & 1566 & 795 \\
\hline AA/P-b-CH & 3505,1315 & 2918 & 1750 & 1440 & ----- & ------ & ----- & 783 \\
\hline
\end{tabular}

Table 2: FT-IR wavenumbers of the characteristic bands of physical cross-linked hydrogels

\begin{tabular}{|c|c|c|c|c|c|c|c|c|c|}
\hline \multirow{2}{*}{$\begin{array}{l}\text { Examined } \\
\text { Sample }\end{array}$} & \multicolumn{9}{|c|}{ Wavenumber of characteristic band, $\mathrm{cm}^{-1}$} \\
\hline & $\mathrm{Y}(\mathrm{O}-\mathrm{H}) \mathrm{str}$ & $(\mathrm{C}-\mathrm{H}) \mathrm{str}$ & $(\mathrm{C}=\mathrm{O}) \mathrm{str}$ & $\mathrm{Y}(\mathrm{C}-\mathrm{O}) \mathrm{str}$ & $\mathrm{Y}(\mathrm{C}-\mathrm{O}-\mathrm{C}) \mathrm{str}$ & $(\mathrm{N}-\mathrm{H}) \mathrm{str}$ & $\mathrm{Y}(\mathrm{C}-\mathrm{N}) \mathrm{str}$ & (C-H)def & $\mathrm{Y}(\mathrm{P}-\mathrm{O}-\mathrm{P}) \mathrm{str}$ \\
\hline $\mathrm{CMC} / \mathrm{P}-\mathrm{b}-\mathrm{PH}$ & $\begin{array}{c}3476 \\
1315\end{array}$ & 2936 & $\begin{array}{l}1650 \\
1740\end{array}$ & 1443 & 1150 & ------ & ------ & 792 & $\begin{array}{c}722,1150, \\
1100,1280\end{array}$ \\
\hline $\mathrm{PE} / \mathrm{P}-\mathrm{b}-\mathrm{PH}$ & $\begin{array}{c}3550, \\
1319\end{array}$ & 2950 & $\begin{array}{l}1738, \\
1603\end{array}$ & 1435 & 1148 & $\begin{array}{ll}----- \\
\end{array}$ & $\begin{array}{ll}----- \\
\end{array}$ & 789 & $\begin{array}{c}710,1148, \\
1095,1290\end{array}$ \\
\hline $\mathrm{CS} / \mathrm{P}-\mathrm{b}-\mathrm{PH}$ & $\begin{array}{l}3482, \\
1320\end{array}$ & 2920 & $\begin{array}{l}1750, \\
1650\end{array}$ & 1440 & 1150 & 3280 & 1540 & 727 & $\begin{array}{l}727,1150, \\
1090,1270\end{array}$ \\
\hline $\mathrm{AA} / \mathrm{P}-\mathrm{b}-\mathrm{PH}$ & 3506 & 3090 & 1742,1603 & 1402 & ------ & ------ & ------ & 799 & 720,1153 \\
\hline
\end{tabular}

Similarly in PE/P-b-CH and PE/P-b-PH hydrogels also have shown characteristic bands Fig. (2) and Tables (1 and 2) almost same for carboxyl and hydroxyl groups of pectin beside the hydroxyl group of PVA (Baum et al., 2017) and only diverse in their functional groups of cross-link type. The FT-IR spectra of chitosan has shown amid-I and amid-II beside carbonyl functional groups (Bisen et al., 2007) which are characteristic bands Fig. (3) and Tables (1 and 2) all are 
shown in both $\mathrm{CS} / \mathrm{P}-\mathrm{b}-\mathrm{CH}$ and $\mathrm{CS} / \mathrm{P}-\mathrm{b}-\mathrm{PH}$ hydrogels and the cross-linker was the only the difference between them. Finally carboxylic acid groups of acrylic acid beside the hydroxyl group of PVA were characteristic bands of $\mathrm{AA} / \mathrm{P}-\mathrm{b}-\mathrm{CH}$ and $\mathrm{AA} / \mathrm{P}-\mathrm{b}-\mathrm{PH}$ hydrogels and the only differences in their FTIR spectra Tables (1 and 2) and Fig. (4) were the functional groups of the cross-linker.

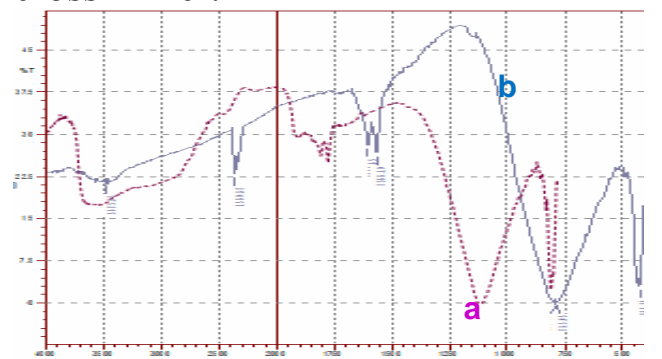

Fig. 1: FT-IR spectra of a.CMC/P-b-CH and b. CMC/P-b-PH hydrogels

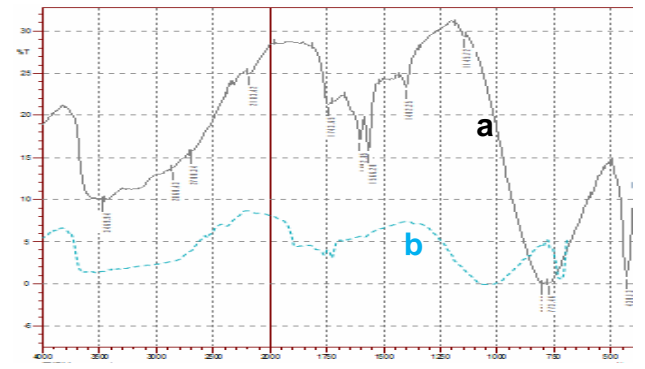

Fig. 3: FT-IR spectra of a. CS/P-b-CH and b. CS/P-b-PH hydrogels

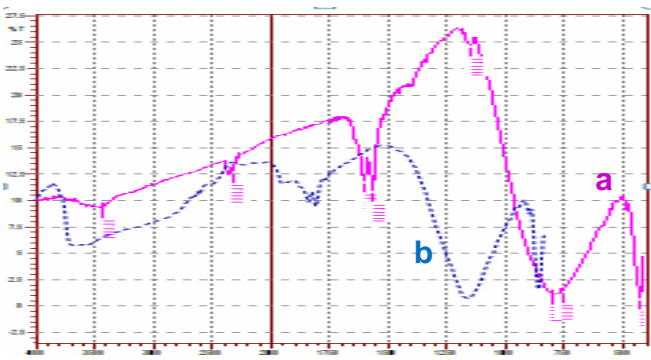

Fig. 2: FT-IR spectra of a. PE/P-b-CH and b. PE/Pb-PH hydrogels

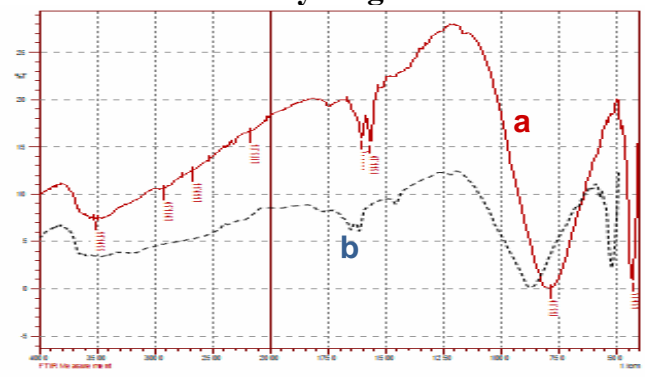

Fig. 4: FT-IR spectra of a. AA/P-b-CH and b. AA/P-b-PH hydrogels

\section{X-ray diffraction}

The XRD pattern data recorded in (Table 3) are shown five peaks some are intense and other are broad for $\mathrm{CMC} / \mathrm{P}-\mathrm{b}-\mathrm{CH}$ hydrogel. The peaks positions at $2 \theta$ axis have shown almost three different crystalline material in the hydrogel. The full width at half maximum (FWHM) of the broadened line along of CMC polymer in the hydrogel was depended for calculation of the area under peaks. Therefore, the percent crystallinity of CMC polymer in the hydrogel, (Table 3) is shown broad peak which give indication that $\mathrm{CMC}$ is non crystallizable and will decrease the crystallinity of the hydrogel necessarily.

Table 3: XRD intensity scan values of chemically cross-linked hydrogels

\begin{tabular}{|c|c|c|c|c|c|c|}
\hline $\begin{array}{l}\text { Examined } \\
\text { sample }\end{array}$ & Peaks at $2 \theta^{0}$ & $\begin{array}{c}\text { Interplanar } \\
\text { distance "d" } \\
\left(\mathbf{A}^{0}\right)\end{array}$ & $\begin{array}{c}\text { FWHM } \\
\qquad\left(\mathbf{A}^{0}\right)\end{array}$ & $\begin{array}{c}\text { Crystalline } \\
\text { phase }\left(\mathbf{A}_{c}\right)\left(\mathbf{A}^{0}\right)\end{array}$ & $\begin{array}{l}\text { Amorphousness } \\
\text { phase }\left(\mathbf{A}_{\mathrm{a}}\right)\left(\mathbf{A}^{0}\right)\end{array}$ & $\begin{array}{c}\text { Crystallinity } \\
\text { percentage } \\
\left(\mathbf{X}_{\mathrm{c}}\right)(\%)\end{array}$ \\
\hline \multirow{5}{*}{$\begin{array}{c}\text { CMC/P-b- } \\
\text { CH }\end{array}$} & 42.095 & 2.146 & 0.230 & 126.90 & 962.80 & 11.65 \\
\hline & 44.693 & 2.027 & 0.307 & 111.38 & 1013.28 & 9.90 \\
\hline & 49.149 & 1.853 & 0.256 & 73.44 & 973.00 & 7.02 \\
\hline & 72.630 & 1.302 & 0.231 & 671.98 & 823.61 & 44.93 \\
\hline & 88.217 & 1.107 & 0.512 & 328.14 & 897.53 & 26.77 \\
\hline \multirow{2}{*}{$\begin{array}{c}\text { PE/P-b- } \\
\text { CH }\end{array}$} & 8.227 & 10.747 & 0.819 & 210.17 & 558.90 & 27.33 \\
\hline & 72.777 & 1.299 & 0.409 & 17.20 & 217.78 & 7.32 \\
\hline \multirow{4}{*}{$\begin{array}{c}\text { CS/P-b- } \\
\text { CH }\end{array}$} & 42.152 & 2.144 & 0.256 & 30.44 & 236.17 & 11.42 \\
\hline & 49.167 & 1.853 & 0.307 & 26.51 & 255.23 & 9.41 \\
\hline & 72.664 & 1.301 & 0.179 & 51.06 & 154.17 & 24.88 \\
\hline & 88.351 & 1.106 & 0.614 & 30.47 & 120.63 & 20.17 \\
\hline \multirow{3}{*}{$\begin{array}{l}\text { AA/P-b- } \\
\text { CH }\end{array}$} & 44.657 & 2.0293 & 0.154 & 16.29 & 709.32 & 2.25 \\
\hline & 72.650 & 1.301 & 0.358 & 135.59 & 426.43 & 24.13 \\
\hline & 88.411 & 1.106 & 0.614 & 67.92 & 404.40 & 14.38 \\
\hline
\end{tabular}


Whereas, the sharp and narrow peaks of PVA alone before blending give high crystallinity, but its blend in the CMC/P-b-CH hydrogel beside the cross-linker, PVA polymer start loss part of its crystallinity (Table 3 ). Finally, the $\mathrm{CMC} / \mathrm{P}-\mathrm{b}-\mathrm{CH}$ hydrogel loss its crystallinity because crystal degree of PVA chains is reduce through breaking down the inter chain hydrogel bonding along the PVA chains (Deshpande et al., 2011).

The XRD patterns of PE/P-b-CH, CS/P-b-CH and AA/P-b-CH hydrogels are tend to noncrystallizable especially in case of pectin hydrogel because of its high amorphousness of the polymer, but their amorphousness would reduce when sodium hydroxide was added because of the high crystallinity of its sodium ions (Hermans and Weidinger, 1951). As it is clear, in CMC/P-b-CH hydrogel where it is in sodium form. Even in AA/P-b-CH hydrogel, the percent crystallinity is depressed inside the hydrogel because blending will decay the regularity of PVA chains (Deshpande et al., 2012).

The physical cross-linked hydrogels in presence of SHMP with its huge quantities of sodium ion will elevate the degree of the blend hydrogels, where CMC/P-b-PH hydrogel (Table 4), shows PVA peaks appeared with atypical sharp and narrow shape with high intensity, which will elevate the whole crystallinity of the hydrogel structure.

Similarly, PE/P-b-PH hydrogel has reach high percent crystallinity and it is expected that the $\mathrm{CS} / \mathrm{P}-\mathrm{b}-\mathrm{PH}$ hydrogel and AA/P-b-PH hydrogel also their percent crystallinity were elevate due to the presence of crystalline SHMP cross-linker.

Table 4: XRD intensity scan value of some physically cross- linked hydrogels

\begin{tabular}{|c|c|c|c|c|c|c|}
\hline $\begin{array}{l}\text { Examined } \\
\text { Sample }\end{array}$ & $\begin{array}{l}\text { Peaks at } \\
2 \theta^{\circ}\end{array}$ & $\begin{array}{c}\text { Interplanar } \\
\text { distance "d" }\left(\mathrm{A}^{0}\right)\end{array}$ & $\begin{array}{c}\text { FWHM } \\
\left(\mathbf{A}^{\mathbf{0}}\right)\end{array}$ & $\begin{array}{c}\text { Crystalline } \\
\text { phase }\left(\mathbf{A}_{c}\right) \\
\left(\mathbf{A}^{0}\right)\end{array}$ & $\begin{array}{c}\text { Amorphousness } \\
\text { phase }\left(A_{a}\right)\left(A^{0}\right)\end{array}$ & $\begin{array}{c}\text { Crystallinity } \\
\text { percentage }\left(X_{c}\right)(\%)\end{array}$ \\
\hline \multirow{6}{*}{ 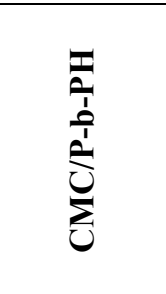 } & 19.845 & 4.474 & 0.921 & 563.36 & 594.18 & 48.67 \\
\hline & 42.116 & 2.146 & 0.307 & 73.41 & 731.83 & 9.12 \\
\hline & 44.667 & 2.029 & 0.154 & 32.54 & 729.75 & 4.27 \\
\hline & 49.132 & 1.854 & 0.409 & 48.81 & 665.71 & 6.83 \\
\hline & 72.664 & 1.301 & 0.102 & 122.77 & 617.83 & 16.58 \\
\hline & 88.257 & 1.107 & 0.409 & 137.40 & 686.31 & 16.68 \\
\hline \multirow{6}{*}{$\frac{\frac{\pi}{a}}{\frac{1}{a}} \frac{1}{\frac{1}{a}}$} & 24.314 & 3.661 & 0.818 & 19.54 & 339.02 & 5.45 \\
\hline & 42.131 & 2.145 & 0.154 & 69.69 & 910.66 & 7.11 \\
\hline & 44.711 & 2.027 & 0.307 & 89.93 & 928.00 & 8.56 \\
\hline & 49.158 & 1.853 & 0.256 & 54.07 & 869.38 & 5.86 \\
\hline & 72.643 & 1.302 & 0.205 & 310.52 & 673.98 & 31.54 \\
\hline & 88.373 & 1.106 & 0.461 & 247.85 & 784.13 & 24.02 \\
\hline
\end{tabular}

\section{Thermal Studies}

Differential thermal analysis DTA of the pristine hydrogel were investigated, DTA thermograms gives thermal information about the studies hydrogel such as glass transition temperature $\mathrm{T}_{\mathrm{g}}$, maximum decomposition temperature $\mathrm{T}_{\max }$, crystalline temperature $\mathrm{T}_{\mathrm{cr}}$ and heat of function $\Delta \mathrm{H}_{\mathrm{f}}$ which are important parameter give good information about the endo-and exo-thermic transition of the hydrogel as a function of temperature.

Thermoanalytical data recorded in (Table 5) give the thermal analysis characterizations of the four tested hydrogel samples cross-linked chemically. The $\mathrm{CMC} / \mathrm{P}-\mathrm{b}-\mathrm{CH}$ hydrogel has shown $\mathrm{T}_{\mathrm{g}}$ at $119.9^{\circ} \mathrm{C}$ means the hydrogel is thermaly stable, and its $\mathrm{T}_{\max }$ and $\mathrm{T}_{\mathrm{cr}}$ at $435^{\circ} \mathrm{C}$ and $400^{\circ} \mathrm{C}$ respectively (Table 5), Fig. (5). Means the hydrogel decomposed at $435^{\circ} \mathrm{C}$ and loss its structure and at $400^{\circ} \mathrm{C}$ start loss its crystalline structure and be ready for decomposition. The heat of function $\Delta \mathrm{H}_{\mathrm{f}}$ of the hydrogel gives two important transitions (Table 5), Fig.(5), one is endotherm of $+45.8{\mathrm{~J} . \mathrm{g}^{-1}}^{-1}$ give indications that the hydrogel components (CMC and PVA) and the sodium ions present in the hydrogel would left the hydrogel has some crystalline portions in its morphology therefore it need 
energy of 45.8 joule per gram for decomposition of those crystalline portions. Whereas the $-5.8 \mathrm{~J} . \mathrm{g}^{-1}$ means the hydrogel has amorphous portions and on decomposition will liberate energy 5.8 Joule per gram of the hydrogel (El- Naggar et al., 2017).

According to the Table 5, PE/P-b-CH, CS/P-b-CH and AA/P-b-CH hydrogel have shown thermal analysis data almost very close to $\mathrm{CMC} / \mathrm{P}-\mathrm{b}-\mathrm{CH}$ hydrogel, where their $\mathrm{T}_{\mathrm{g}}, \mathrm{T}_{\max }$ and $\mathrm{T}_{\text {cr }}$ Figs. (6-8) are recorded also at high temperature which means they have high thermal stability and even shows $\Delta \mathrm{H}_{\mathrm{f}}$ of two transitions one endo-and other exo-thermic transitions but with different magnitudes depends on crystalline and amorphous portions in the hydrogel structure (Fan et al., 2016).

Table 5: DTA thermal data of chemically cross-linked hydrogels

\begin{tabular}{|c|c|c|c|c|}
\hline Examined sample & $\mathbf{T}_{\mathbf{g}}\left({ }^{\mathbf{0}} \mathbf{C}\right)$ & $\mathbf{T}_{\max }\left({ }^{\mathbf{0}} \mathbf{C}\right)$ & $\left.\mathbf{T}_{\text {cr }}{ }^{\mathbf{0}} \mathbf{C}\right)$ & $\Delta \mathbf{H}_{\mathbf{f}}\left(\mathbf{J . g}^{-\mathbf{1}}\right)$ \\
\hline $\mathbf{C M C} / \mathbf{P}-\mathbf{b}-\mathbf{C H}$ & 119.9 & 435 & 400 & $+32.2 ;-5.8$ \\
\hline $\mathbf{P E} / \mathbf{P}-\mathbf{b}-\mathbf{C H}$ & 103.7 & 420 & 408 & $+15.8 ;-6.0$ \\
\hline $\mathbf{C S} / \mathbf{P}-\mathbf{b}-\mathbf{C H}$ & 111.6 & 431 & 399 & $+25.3 ;-25.9$ \\
\hline $\mathbf{A A} / \mathbf{P}-\mathbf{b}-\mathbf{C H}$ & 114.2 & 420 & 416 & $+47.5 ;-7.2$ \\
\hline
\end{tabular}

The physical cross-linking hydrogels have shown thermal analysis Table 6 and Figs. (5-8) with completely different thermograms, The main differences recorded in physical cross-linked hydrogels in comparison with those cross-linked chemically are the little depression in their thermal parameters represent $\mathrm{T}_{\mathrm{g}}, \mathrm{T}_{\max }$ and $\mathrm{T}_{\mathrm{cr}}$ and especially in case of CMC/P-b-PH, CS/P-b-PH and AA/P-b-PH Fig. (5), Fig. (7) and Fig. (8) respectively due to their weak crystalline structure and this is clear from their $\Delta \mathrm{H}_{\mathrm{f}}$, where their endo-thermic transitions are little depress in comparison with the chemical cross-linked hydrogels and their exo-thermic transitions are elevate which means the physical cross-linked hydrogels are less thermally stable due to the easier collapse of their systems (Akhtar and Ranjha, 2016), whereas PE/P-b-PH hydrogel (Table 3-6 and Fig. 6), where pectin with SHMP could increase its crystallinity and enhance the crystallographical structure of the hydrogel.

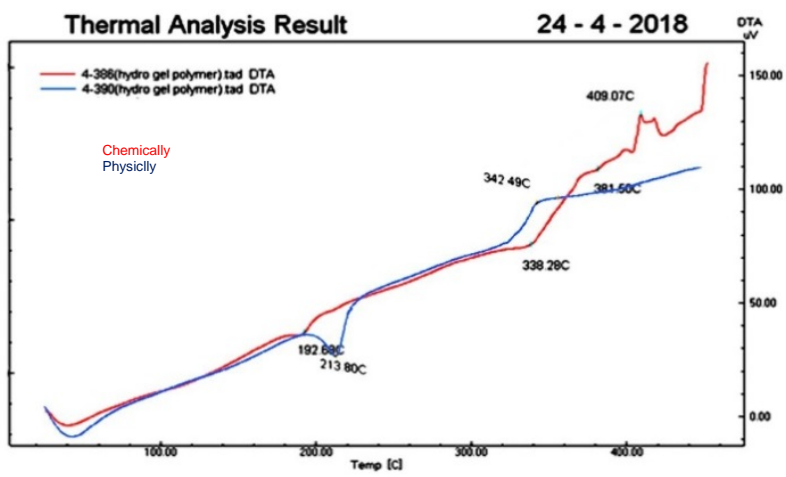

Fig. 5: DTA of CMC/P-b-CH \& CMC/P-b-PH hydrogels

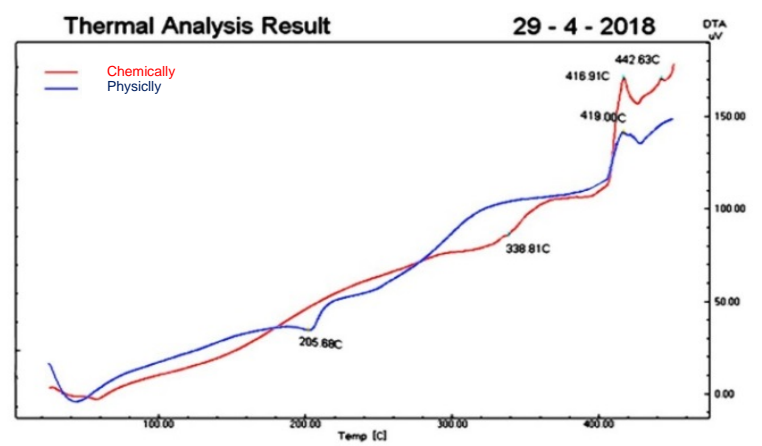

Fig. 6: DTA of PE/P-b-CH \& PE/P-b-PH hydrogels

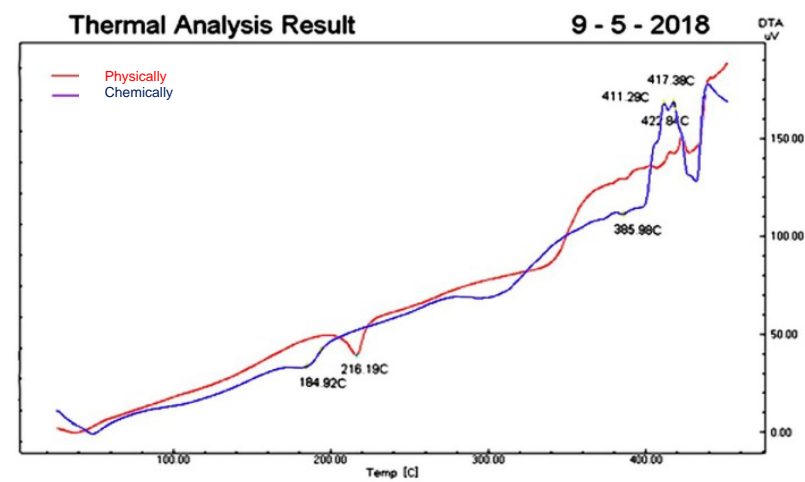

Fig. 7: DTA of CS/P-b-CH \& CS/P-b-PH hydrogels

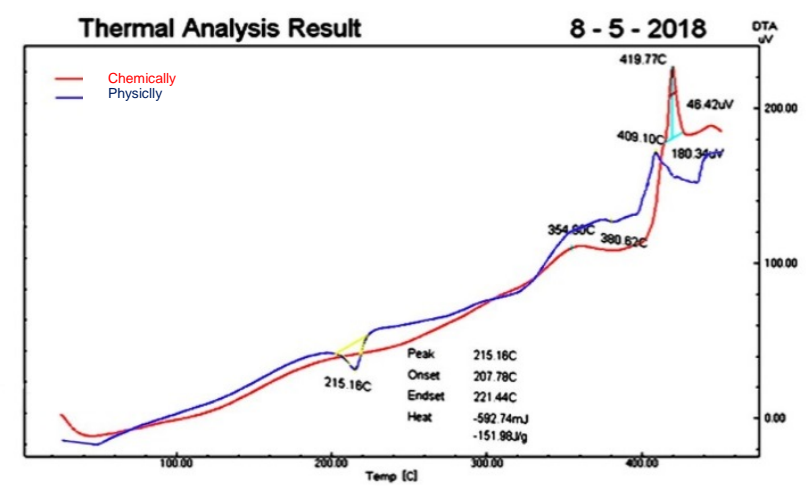

Fig. 8: DTA of AA/P-b-CH \& AA/P-b-PH hydrogels 
Table 6: DTA thermal data of physically cross-linked hydrogels

\begin{tabular}{|c|c|c|c|c|}
\hline Examine sample & $\mathbf{T}_{\mathbf{g}}\left(\mathbf{C}^{\circ}\right)$ & $\mathbf{T}_{\max }\left(\mathbf{C}^{\circ}\right)$ & $\mathbf{T}_{\mathbf{c r}}\left(\mathbf{C}^{\circ}\right)$ & $\Delta \mathbf{H}_{\mathbf{f}}\left(\mathbf{J . g}^{-\mathbf{1}}\right)$ \\
\hline $\mathbf{C M C} / \mathbf{P}-\mathbf{b}-\mathbf{P H}$ & 106.2 & 358 & 320 & $+16.3 ;-200.0$ \\
\hline $\mathbf{P E} / \mathbf{P}-\mathbf{b}-\mathbf{P H}$ & 115.4 & 433 & 408 & $+11.4 ;-9.5$ \\
\hline $\mathbf{C S} / \mathbf{P}-\mathbf{b}-\mathbf{P H}$ & 104.5 & 397 & 341 & $+15.1 ;-34.4$ \\
\hline AA/P-b-PH & 74.9 & 412 & 398 & $+13.8 ;-23.0$ \\
\hline
\end{tabular}

\section{SEM images}

SEM studies and composite morphologies of the tested hydrogels are illustrates in Figs. (912) where $\mathrm{CMC} / \mathrm{P}-\mathrm{b}-\mathrm{CH}$ has shown in Fig. (9) folded surface and its blend components are homogenously distributed and its surface seems to be suitable for highly loading of liquids or solid materials. Whereas CMC/P-b-PH hydrogel Fig. (9) has shown smooth surface with a lot of pores and cavities and seems to be more compact (Pourjavadi et al.,2007).The PE/ P-b-CH hydrogel SEM image has shown irregular and folded surface with a lot of cavities Fig. (10), while PE/P-b-PH hydrogel Fig. (10) has SEM image shows smooth and porous surface and compact form. Same photograms have seen in case of $\mathrm{CS} / \mathrm{P}-\mathrm{b}-\mathrm{CH}$ and $\mathrm{CS} / \mathrm{P}-\mathrm{b}-\mathrm{PH}$ hydrogels Fig. (11), where the hydrogel's surface was rough with many folds and shown cavities between the folds with many pores distributed irregularly between folds (Fan et al., 2016). Similarly the CS/P-b-PH hydrogels has shown less fold surface with cracks Fig.11 and white spots represent same unmixed well components of the hydrogel which effect of course on its homogeneousity.
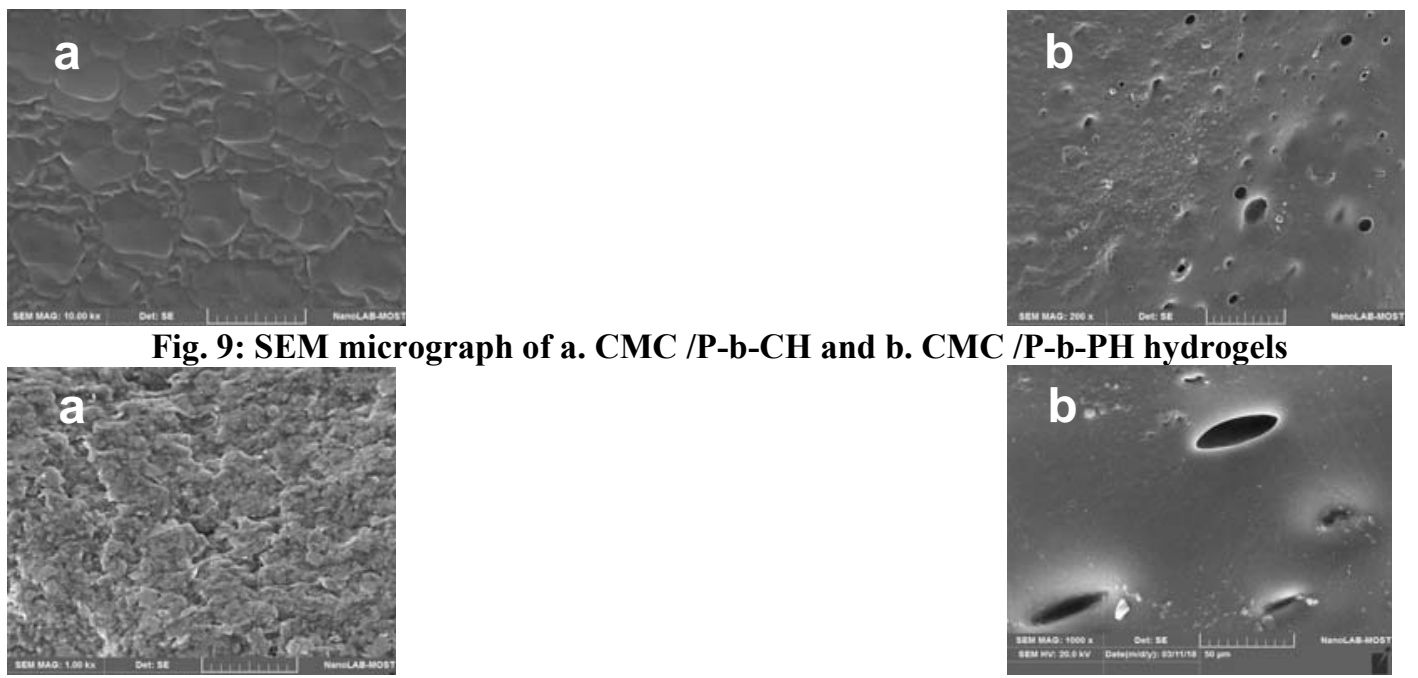

Fig. 10: SEM micrograph of a. PE /P-b-CH and b. PE /P-b-PH hydrogels

The AA/P-b-CH hydrogel has shown SEM image of transparent crystalline surface Fig. (12) contain cut away of compact crystals in its composite structure. In addition the cavities and pores are in between the crystals which will help for loading materials (Pourjavadi et al.,2007). The AA/P-b-PH hydrogel give highly crystalline structure in its SEM photograms Fig. (11), with unhomogeneous surface seems to be unable for loading materials in high quantities. 

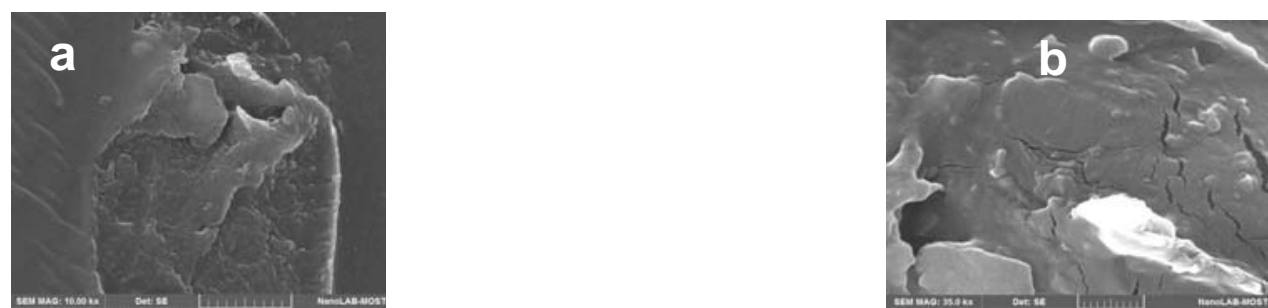

Fig. 11: SEM micrograph of a. CS /P-b-CH and b. CS /P-b-PH hydrogels
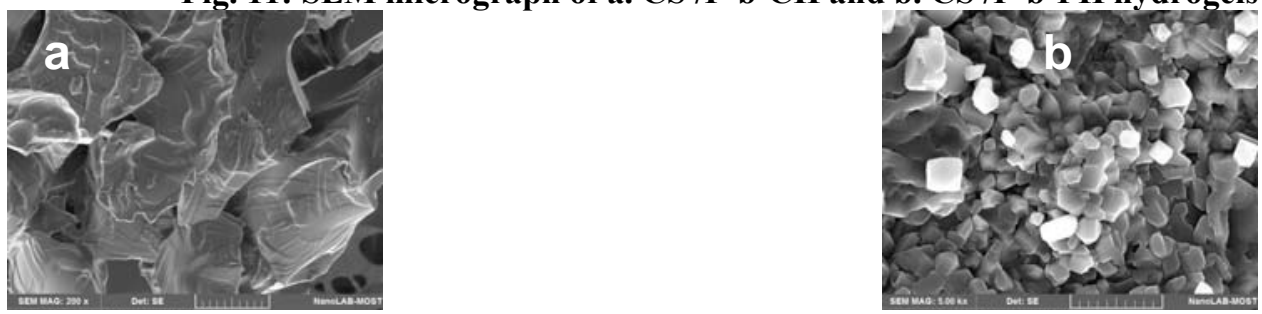

Fig. 12: SEM micrograph of a. AA/P-b-CH and b. AA/P-b-PH hydrogels

\section{Studies on degree of swelling $\left(\mathrm{S}_{\mathrm{W}}\right)$}

The degree of swelling of the preparedhydrogels in different $\mathrm{pH}$ swelling medium were investigated for best swelling conditions and in $0.1 \mathrm{~N}$ saline solutionthe degree of swelling also was examined. The degrees of swelling of CMC/P-b-CH and CMC/P-b-PH hydrogels were measured according to the Eq. 2, using swelling medium of $\mathrm{pH} 4, \mathrm{pH} 7$ and $\mathrm{pH} 9$ in addition to $0.1 \mathrm{~N} \mathrm{NaCl}$. Fig. (13) shows significant effects of $\mathrm{pH}$ or ionic solution of swelling medium on $\mathrm{S}_{\mathrm{W}}$ (Salmawi, 2007). Where $\mathrm{pH} 7$ seems better $\mathrm{pH}$ swelling medium for $\mathrm{CMC} / \mathrm{P}-\mathrm{b}-\mathrm{CH}$ hydrogel Fig. (13) while pH9 was better as $\mathrm{pH}$ swelling medium for CMC/P-b-PH hydrogel Fig. (13), because the basic medium would provide extra anions beside the anions of the physical cross- linker and as a result the repulsions between polymer chains will increase which elevate the hydrogel volume and finally increase its degree of swelling. Whereas, $\mathrm{CMC} / \mathrm{P}-\mathrm{b}-\mathrm{CH}$ hydrogel has its maximum degree of swelling in pH7 Fig.(13), because the hydrogel is neutral and has no ionic structure and the swelling control factor is the penetration capability of the solvent molecules between polymer chains. In pH4, both hydrogels have shown low degree of swelling Fig.(13), because they shrink in acidic medium and especially CMC/P-b-PH due to neutralization of its anions with acid cations of the swelling medium Fig. (13). The swelling medium $0.1 \mathrm{~N} \mathrm{NaCl}$ has a significant effect on the $\mathrm{S}_{\mathrm{w}}$ of the hydrogels. The saline solution will effect on both $\mathrm{CMC} / \mathrm{P}-\mathrm{b}-\mathrm{CH}$ and $\mathrm{CMC} / \mathrm{P}-\mathrm{b}-\mathrm{PH}$ hydrogel Fig.13 because $\mathrm{NaCl}$ the strong electrolyte when dissociate will prevent hydrogen boinding in $\mathrm{CMC} / \mathrm{P}-\mathrm{b}-\mathrm{CH}$ hydrogel and decrease $\mathrm{S}_{\mathrm{w}}$, beside it prevent the ionic interaction between polymer chains of CMC/P-b-PH hydrogel and decrease its $\mathrm{S}_{\mathrm{w}}$.

For PE/P-b-CH and PE/P-b-PH hydrogels are shown maximum $\mathrm{S}_{\mathrm{w}}$. Therefore, $\mathrm{PE} / \mathrm{P}-\mathrm{b}-\mathrm{CH}$ at pH9 same like CMC/P-b-CH hydrogel Fig. (14), while PE/P-b-PH has shown more swelling in pH4 due to its carboxylic groups Fig. (14). However, Chitosan the cationic natural polymer its hydrogel $\mathrm{CS} / \mathrm{P}-\mathrm{b}-\mathrm{CH}$ has high degree of swelling in comparison with physical cross-linked hydrogel Fig. (15), whereas AA/P-b-CH hydrogel has shown high swelling in $\mathrm{pH} 9$ due to repulsion between carboxylate anions of the acrylic acid and anions of the $\mathrm{pH} 9$ which elevate the swelling Fig. 16, while the AA/P-b-PH hydrogel shows higher degree of swelling in $\mathrm{pH} 4$ due to repulsion between both $\mathrm{pH} 4$ swelling medium and acrylic acid cations. In addition $0.1 \mathrm{~N} \mathrm{NaCl}$ would help AA/P-b-PH hydrogel for more degree of swelling Fig. (16), due to anions repulsion between the hydrogel chains. 


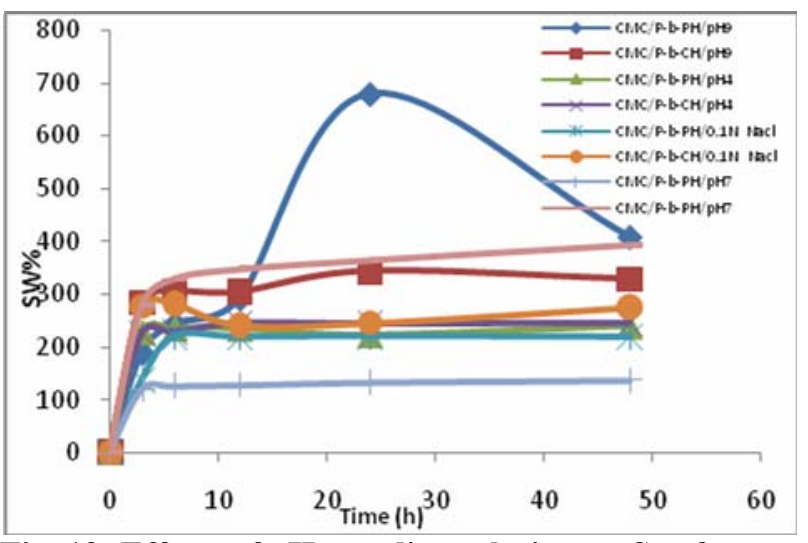

Fig. 13: Effects of $\mathrm{pH}$ or saline solution on $\mathrm{S}_{\mathrm{w}}$. of $\mathrm{CMC} / \mathrm{P}-\mathrm{b}-\mathrm{CH}$ and CMC/P-b-PH hydrogels

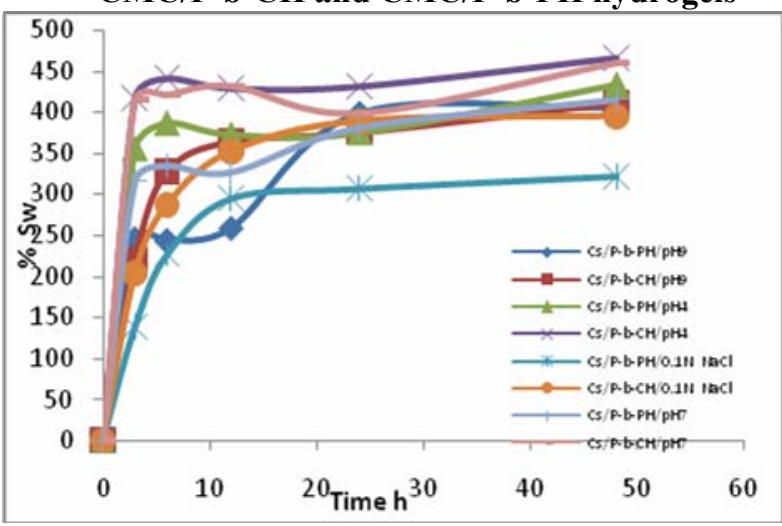

Fig. 15: Effects of $p H$ or saline solution on $S_{w}$.of CS/P-b-CH and CS/P-b-PH hydrogels

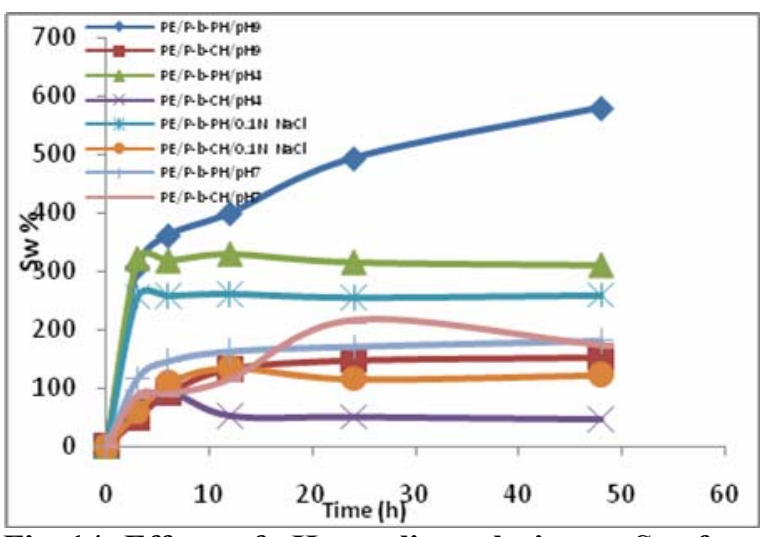

Fig. 14: Effects of pH or saline solution on $S_{w}$.of PE/P-b-CH and PE/P-b-PH hydrogels

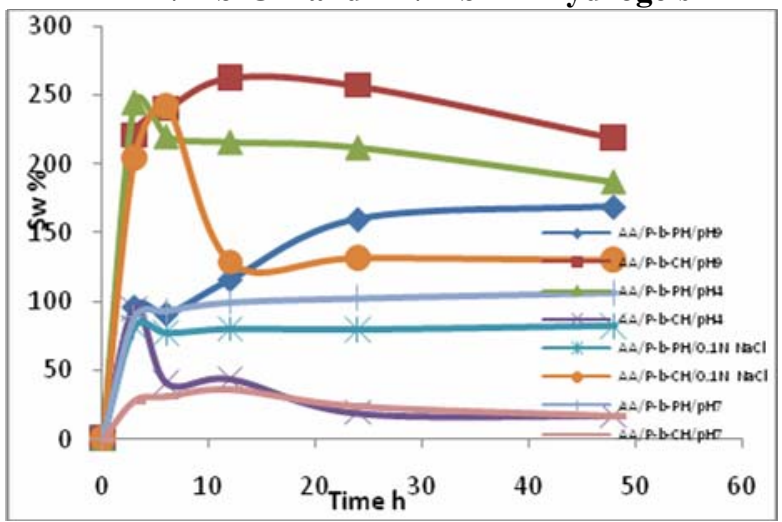

Fig. 16: Effects of $\mathrm{pH}$ or saline solution on $\mathrm{S}_{\mathrm{w}}$.of AA/P-b-CH and AA/P-b-PH hydrogels

\section{Loading of BSA on hydrogels}

Different conditions of BSA loading hydrogels are considered due to their importance to reach maximum loading and to increase the efficiency of loading, therefor UV-Visible technique at $\lambda_{\max } 279 \mathrm{~nm}$ were depended for measuring the absorbance (A) of BSA loaded protein on prepared hydrogels. Loading $\mathrm{pH}$ and its time beside the concentration of BSA used for loading were investigated. The Eqs. (3 and 4) are considered for determination of maximum loading percentage $\left(\% \mathrm{~L}_{\max }\right)$ and the efficiency loading percentage $(\% \mathrm{EL})$.

However, loading on hydrogel depends mainly on its swelling degree and as the hydrogel swell more will be load more. Accordingly, because degree of swelling is affected significantly with $\mathrm{pH}$, therefore $\mathrm{pH}$ control swelling and swelling play an important role in hydrogel loading. Fig. (17) has shown the efficiency of BSA loading (EL) versus $\mathrm{pH}$ solution where in which the hydrogel reach its efficient loading (Rizwan et al., 2017). The time of loading also has significant effects on efficiency of loading, Fig.18 has shown the efficiency of BSA loading versus time in hours. Where the dependence of loading on time is in turn depend on degree of swelling of the hydrogel (Sriamornsak et al., 2010). On account of the hydrogel is need sufficient time to reach its maximum degree of swelling and already when the hydrogel reach maximum swelling means the hydrogel will reach its maximum loading Fig. (18).

From other side, BSA concentration has shown an effect on the efficiency of loading (EL) percentage. Fig. (19) has shown the maximum loading of BSA which depends on the concentration of BSA in order to optimize the economical concentration of BSA in loading solution. The maximum loading of the hydrogels cross-linked chemically or physically are shown depended to their degree of swelling Figs. (17-19) and because physically cross-linked hydrogels have ionic interactions between their chains (Parhi, 2017), they show more effects from the loading conditions than chemically cross-linked hydrogels. 


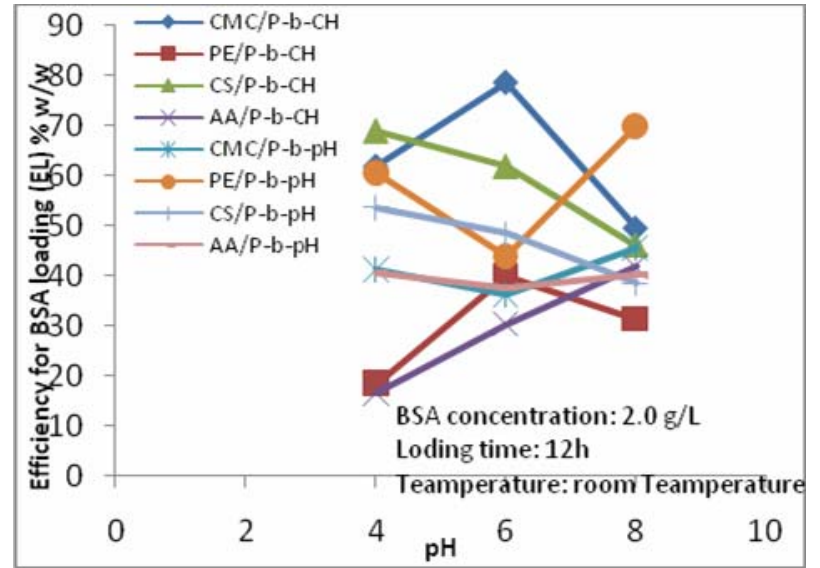

Fig. 17: Efficiency of BSA loading on chemically and physically cross-linked hydrogels for $\mathrm{pH}$ optimization

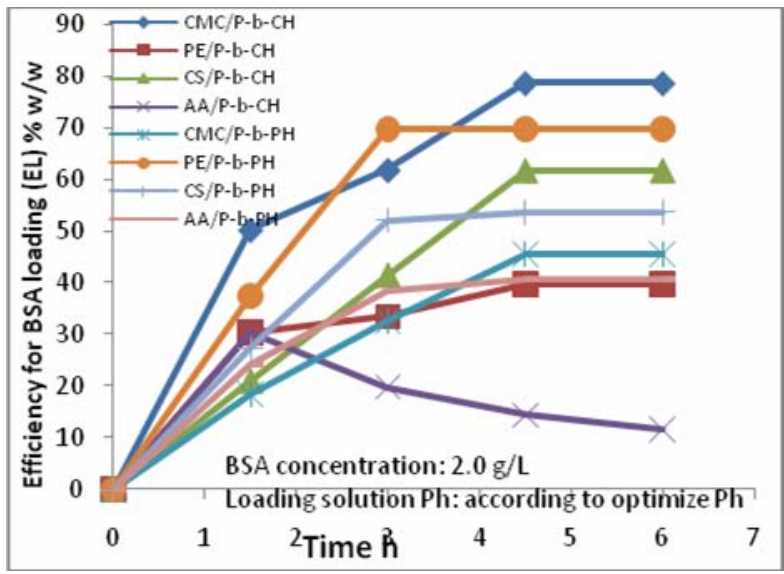

Fig. 18: Efficiency of BSA loading on chemically and physically cross- linked hydrogels for time optimization

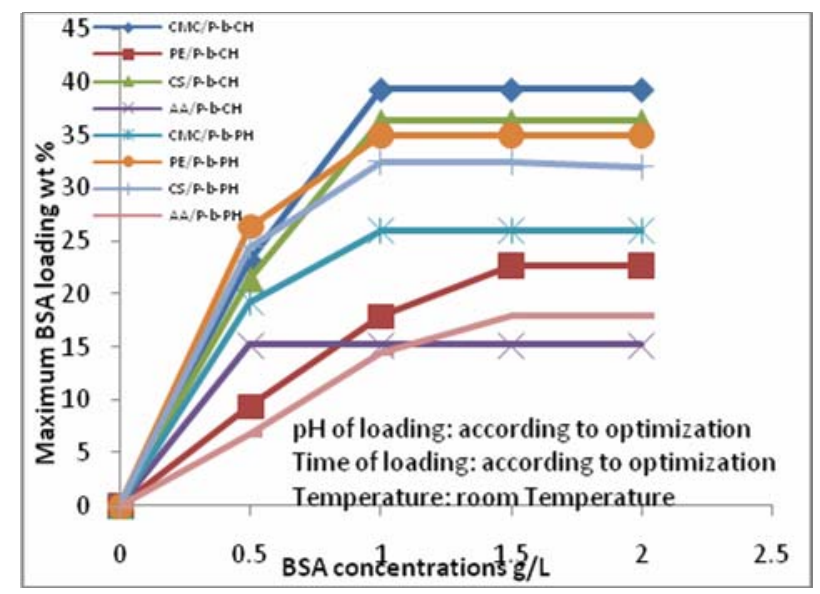

Fig. 19: Maximum BSA loading $\left(\mathrm{L}_{\mathrm{max}}\right)$ chemical and physical cross-linked hydrogels versus concentrations of BSA

\section{Studies on releasing of BSA from hydrogels}

The BSA loaded hydrogels were examined in their cumulative release $\left(R_{\text {cum }}\right)$ percentage for $12 \mathrm{hrs}$ and each time intervals of $3 \mathrm{hrs}$ inside physiological saline (PS) solution which was prepared of $0.9 \% \mathrm{w} / \mathrm{v}$. The release process was examined under two variable conditions are release medium temperature of 15,25 and $40^{\circ} \mathrm{C}$ in addition to the $\mathrm{PH}$ of the release medium as $\mathrm{pH} 4, \mathrm{pH} 6$ and $\mathrm{pH} 8$ and Eq. 5 has been depended in addition to the new calibration curve was prepared in PS solution for calculation the concentrations of BSA release depending on UV-Visible spectrophotometer for determination of the BSA release absorbance (A) at $\lambda_{\max } 279 \mathrm{~nm}$.

The BSA protein was released in PS release solution because BSA hardly diffuse in D.W., Whereas the Saline ions prevent non-ionic interaction by ordering the structure of water (Rose, 1989). So that the BSA protein molecules absorbed on hydrophobic groups of the hydrogel could release easily in saline solution (Oztop et al., 2003; Wang et al.,2018; Asenjo and Andrews, 2011).

The degree of release of the hydrogel is in concert with its degree of swelling but this truth is in D.W. whereas it shows swelling loss in saline solution (Hosseinzadeh, 2013).

The CMC/P-b-CH hydrogel loaded with $\% \mathrm{~L}_{\max }=39.3 w t \%$ BSA has shown depression in its $\% \mathrm{R}_{\text {sum }}$ in comparison with its $\% \mathrm{~L}_{\max }$ which means some of BSA protein was remained inside the hydrogel and not release completely and the hydrogel record its best release in pH6 and at $15^{\circ} \mathrm{C}$ Fig. (20), with $\% \mathrm{R}_{\text {sum }}=26.2 \mathrm{wt} \%$ and record release efficiency percentage of $66.7 \%$. The CMC/P$\mathrm{b}-\mathrm{CH}$ hydrogel has shown minimum release in acidic and basic medium due to the ionic interaction with the ions of the release medium (El- Naggar et al., 2017). Whereas the CMC/P-b-PH hydrogel 
has shown its maximum release in basic medium and at $15^{\circ} \mathrm{C}$ Fig. 21 . The $\% \mathrm{~L}_{\max }=26.0 w t \%$ BSA of $\mathrm{CMC} / \mathrm{P}-\mathrm{b}-\mathrm{PH}$ hydrogel would release $\% \mathrm{R}_{\text {sum }}=23.6 \mathrm{wt} \%$ with release efficiency percentage of $90.8 \%$ in $\mathrm{pH} 8$ release medium which increase the repulsions between the hydrogel chains and increase its swelling and finally its cumulative release.

The cumulative release of PE/P-b-CH hydrogel has reached to $\% \mathrm{R}_{\text {sum }}=18.4 w t \%$ of $\% \mathrm{~L}_{\max }=$ $22.7 w t \%$ with release efficiency percentage of $81 \%$ in $\mathrm{pH} 8$ release medium Fig. $(22)$, and at $15^{\circ} \mathrm{C}$ due to the hydrogel internal ions which are tended to anionic categories that enter in repulsions with the ions of the basic medium and therefore increase its degree of swelling and as result its cumulative release (Martínez et al., 2014). Similarly, PE/P-b-PH hydrogel has shown its maximum release also in pH8 but at $25^{\circ} \mathrm{C}$ Fig. 23 for hydrogel has $\% \mathrm{~L}_{\max }=34.9 w t \%$ BSA and its $\% \mathrm{R}_{\text {sum }}=$ $29.5 w t \%$ with release efficiency percentage of $84.5 \%$.

The cationic natural occurring polymer chitosan was considered one of most famous pharmaceutical polymer (Gupta and Jabrial, 2007). Where the CS/P-b-CH hydrogel was loaded with BSA protein and its $\% \mathrm{~L}_{\max }=36.3 \mathrm{wt} \%$ and it was shown its maximum $\% \mathrm{R}_{\text {sum }}=31.6 \mathrm{wt} \%$ in pH4 release medium and at $15^{\circ} \mathrm{C}$ Fig. (24), and $87.0 \%$ efficiency release percentage.

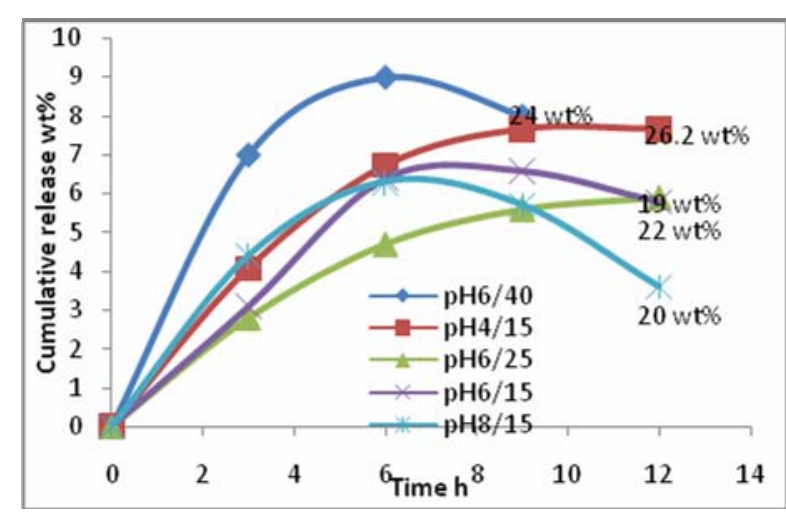

Fig. 20: \% Rcum of CMC/P-b-CH hydrogel

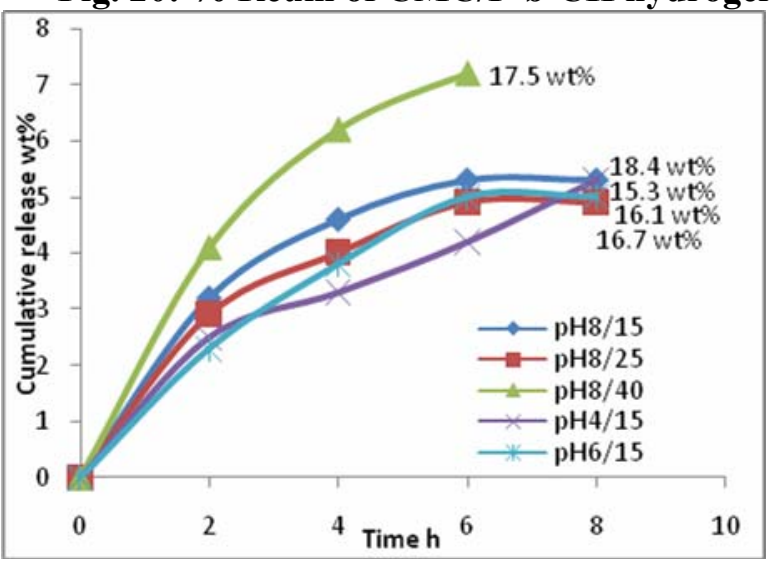

Fig. 22: \% $\mathrm{R}_{\text {cum }}$ of PE/P-b-CH hydrogel

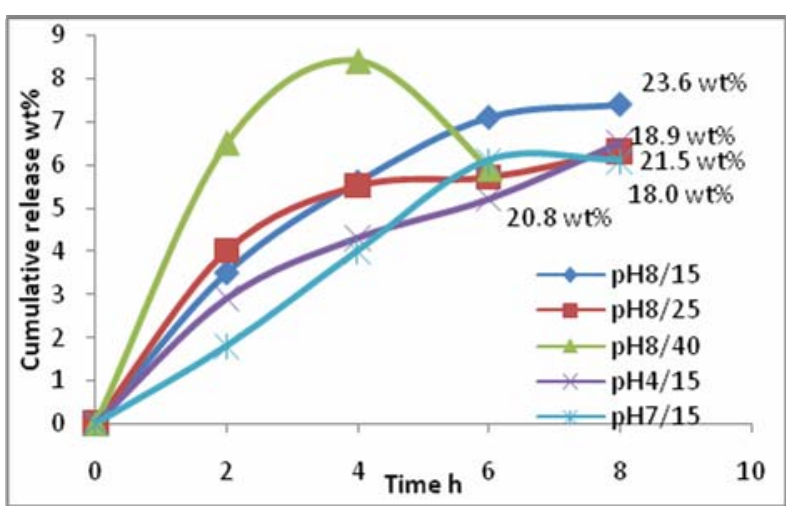

Fig. 21: \% Rcum of CMC/P-b-PH hydrogel

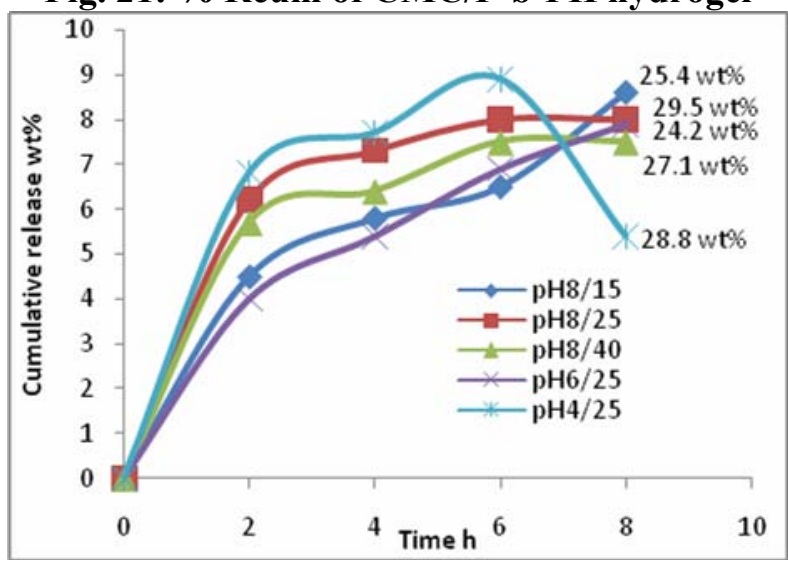

Fig. 23: \% $\mathbf{R}_{\text {cum }}$ of PE/P-b-PH hydrogel

Similarly, the CS/P-b-CH hydrogel has shown its maximum release also in $\mathrm{pH} 4$ and at $25^{\circ} \mathrm{C}$ because of its cationic natural which do repulsions between the hydrogel cations and release medium cations and finally increase the degree of swelling and the maximum cumulative release. The Fig. (25), has shown CS/P-b-PH hydrogel with $\% \mathrm{~L}_{\max }=32.0 w t \%$ BSA and it give $\% \mathrm{R}_{\text {sum }}=$ $28.8 w t \%$ with $90 \%$ efficiency release percentage. 


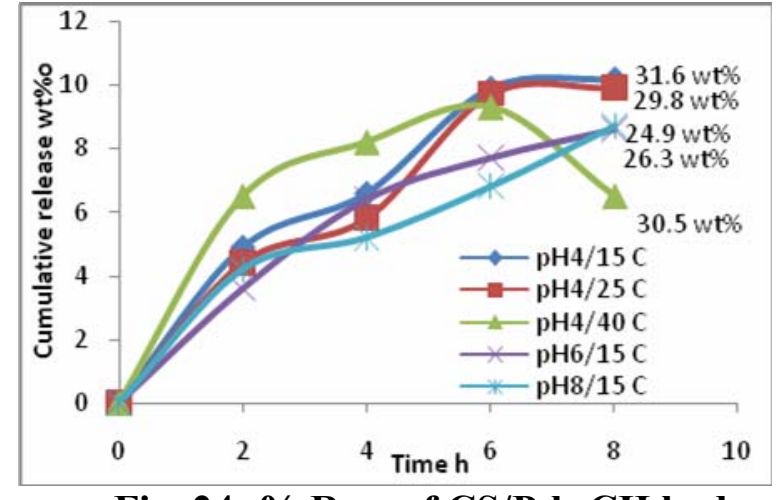

Fig. 24: \% $\mathrm{R}_{\text {cum }}$ of CS/P-b-CH hydrogel

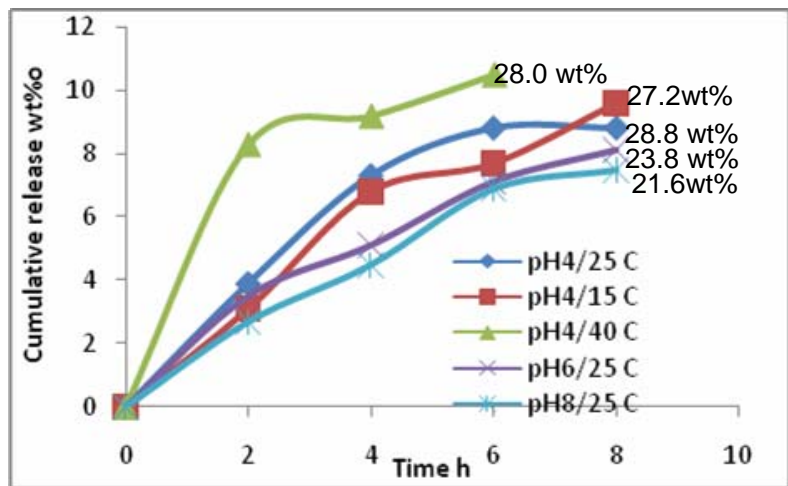

Fig. 25: \% $\mathrm{R}_{\text {cum }}$ of CS/P-b-PH hydrogel

The crystalline AA/P-b-CH structure has shown low maximum loading between its crystals and in between its cavities therefore, its $\% \mathrm{~L}_{\max }=15.2 \mathrm{wt} \%$ and and it give $\% \mathrm{R}_{\text {sum }}=12.6 \mathrm{wt} \%$ Fig. 26 , and with almost high magnitude of efficiency release percentage $82.9 \%$ where BSA molecules like to leave the crystalline structure of the hydrogel in $\mathrm{pH} 8$ release medium due to the competition between BSA anions and the pH8 release medium anions. Also the AA/P-b-PH hydrogel release BSA weakly from hydrogel was loaded with $\% \mathrm{~L}_{\max }=18.0 w t \%$ and its $\% \mathrm{R}_{\text {sum }}=15.9 w t \%$ Fig. (27), with high efficiency of release percentage of $88.3 \%$, but for this hydrogel the $\mathrm{pH} 4$ and $15^{\circ} \mathrm{C}$ temperature were suitable for best release due to the physical cross-linked hydrogel, where its cations help for more repulsions between the chains and its degree of swelling increase and finally it release efficiency percentage would increase.

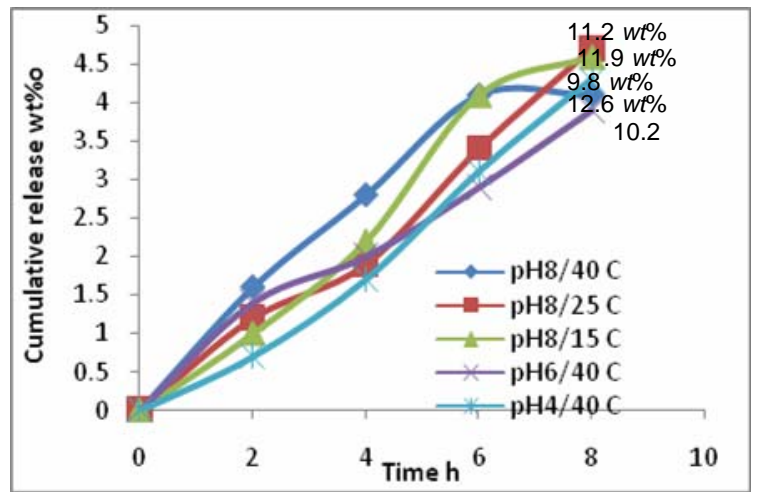

Fig. 26: $\% R_{\text {cum }}$ of $A A / P-b-C H$ hydrogel

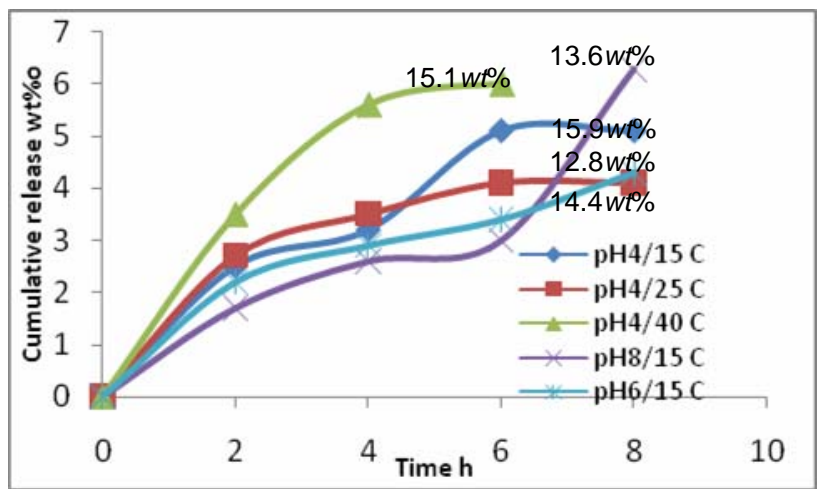

Fig. 27: \% $\mathbf{R}_{\text {cum }}$ of AA/P-b-PH hydrogel

\section{SEM characterization of some hydrogels after release}

The SEM studies have shown the morphological surface of some studied hydrogels after release in order to be sure that the texture structure is still coherent and the hydrogel could be used next. The CMC/P-b-CH and CMC/P-b-PH hydrogels have shown SEM images with surface fill with many folded layers with clefts which may improve its next loading and releasing for different materials Fig.28a and huge of $\mathrm{NaCl}$ crystals are adhered on the surface of CMC/P-b-CH hydrogel. Whereas the CMC/P-b-PH hydrogel surface has SEM images with nice caves and holes most are open and empty and the hydrogel has geometric shape with compact tight form Fig.(28b), which means the hydrogel could be used many times.

The PE/P-b-CH hydrogel has shown SEM images Fig. (29a) with many clear pores on its surface beside white pots give indication of BSA molecules are remain in the hydrogel and the hydrogel is undamaged and could be used next. The texture surface of PE/P-b-PH hydrogel Fig. (29b) shows open holes and it looks like beehive with compact structure could be used next for loading and releasing. 

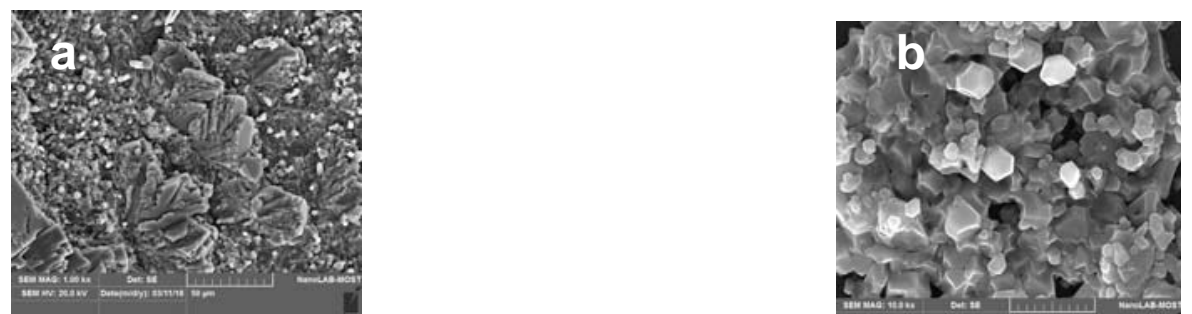

Fig. 28: SEM micrograph of a. CMC/P-b-CH and b. CMC/P-b-PH hydrogels after release
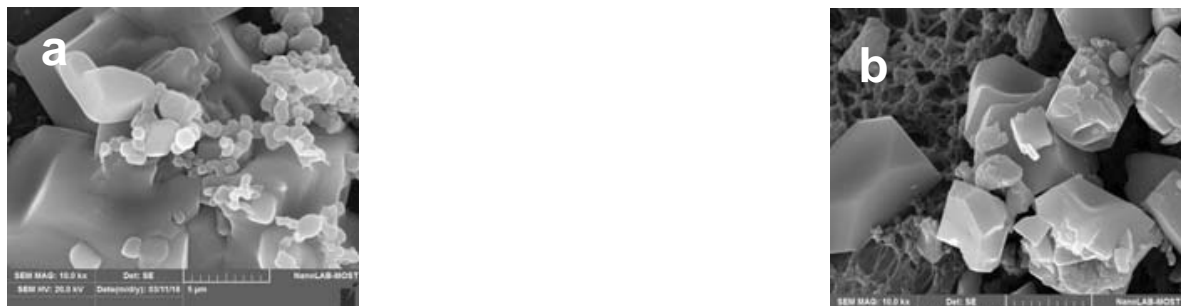

Fig. 29: SEM micrograph of a. PE/P-b-CH and b. PE/P-b-PH hydrogels after release

\section{CONCLUSION}

The PVA blend hydrogels have shown homogeneous materials, the blending would improve the chemical and physical properties and stable them thermally and mechanically, and produce practical morphological surface contain qualifications, allow them for several uses.

The hydrogels were characterized using FTIR for their structure, XRD for their crystallographic structure, DTA and some thermal parameters for their thermal stability and SEM photograms for their morphological analysis. The hydrogels have shown their maximum swelling each in its suitable $\mathrm{pH}$ according to its functional groups. Loading of the hydrogels with BSA protein was success and reach its maximum at suitable time and $\mathrm{pH}$ of loading medium beside suitable BSA concentration. The loaded BSA hydrogels were allowed to release in PS solution and depending suitable $\mathrm{pH}$ and temperature of the release medium.

\section{REFERENCES}

Ahmed, E.M. (2015). Hydrogel: Preparation, characterization, and applications. J. Advan. Res., 6,105-121.

Akhtar, M.F.; Ranjha, N.M. (2016). Methods of Synthesis of Hydrogels... A Review. Saudi Pharm. J., 24(5), 554-559.

Asenjo, J.A.; Andrews, B.S. (2011). Aqueous two-phase systems for protein separation: A perspective. J. Chromat. A, 1218, 8826-8835.

Baum, A.; Dominial, M.; Vidal-Melgosa, S.; Willats, W.G.T.; Sonderguard, K.M. (2017). Prediction of pectin yield and quality by ftir and carbohydrate microarray analysis. Food Bioproc. Tech., 10(1), 143-154.

Bisen, D.S.; Bhatt, R.; Bajpai, A.K.; Bajpai, R.; Katare, R. (2007). Reverse indentation size effects in Gamma Irradiated blood compatible blend films of chitsoan-poly (vinyl alcohol) for possible medical applications. Mat. Sci. Eng. C, 71, 982-993.

Del Valle, L.J.; Díaz, A.; Puiggalí, J. (2017). Hydrogels for biomedical applications: cellulose, chitosan, and protein/peptide derivatives. Gels, 3, 27.

Deshpande, D.S.; Bajpai, R.; Banjpai, A.K. (2011). Synthesis and characterization of acrylonitrile incorporated pva based semi-inter penetrating polymeric networks. Int. J. Chem. Res., 3(3), 74-82.

Deshpande, D.S.; Bajpai, R.; Bajpai, A.K. (2012). Synthesis and characterization of polyvinyl alcohol based semi interpenetrating polymeric networks. J. Polym. Res., 19, 1-9. 
El- Naggar, A.W.M.; Senna, M.M.; Mostafa, T.A.; Helal, R.H. (2017). Radiation synthesis and drug delivery properties of interpenetrating networks (IPNS) based on (Vinyl alcohol)/methyl cellulose Blend Hydrogels. Int. J. Bio. Macro., 102, 1045-1051.

Fan, L.; Yang, H.; Yang, J.; Peng, M.; Hu, J. (2016). Preparation and characterization of chitosan/ Gelatin/ PVA Hydrogel for Wound Dressinfs. Carbohy. Polym. 146, 427-434.

Ghobashy, M.M.; Awad, A.; Elhady, M.A.; Elbarbary, A.M. (2017). Silver rubber-hydrogel nanocomposite as $\mathrm{pH}$-sensitive prepared by gamma radiation: Part I. Cogent Chem., 3, 1328770.

Gomez, F.M.; Guerrero, J.; Matsuhiro, B.; Pavez, J. (2017). "In Vitro Release of Metformin Hydrochloride from sodium Alginate/ Polyvinyl alcohol Hydrogels" Carbohy. Polym.155, 182-191.

Gupta, K.C.; Jabrial, F.H. (2007). Controlled-Release formulations for hydroxy urea and rifampicin using polyphosphate-anion-crosslinked chitosan microsphere. J. Appl. Poly. Sci., 104, 1942-1956

Gupta, K.C.; Jabrial, F.H. (2007). Glutaraldehyde Cross-linked chitosan microspheres for controlled release of centehroman. Carbohy. Res., 342, 2244-2252

Hermans, P.H.; Weidinger, A. (1951). Crystallinity of celluloses after treatment with sodium hydroxide (Mexcerization). J. Polym. Sci., 6(5),533-538.

Hosseinzadeh, H. (2013). Synthesis and swelling properties of a poly(vinyl alcohol)-based superabsorbing hydrogel. Curr. Chem. Lett. 2, 153-158.

Kitsara, M.; Ducr'ee, J. (2013). Integration of functional materials and surface modification for polymeric microfluidic systems. J. Micromech. Microeng., 23, 033001-033020.

Krishna Rao, K.S.V.; Kiran Kumar, A.B.V.; Madhusudhan Rao, K.; Subha, M.C.S.; Lee, Y. (2008). Semi-IPN hydrogels based on Poly(vinyl alcohol) for controlled release studies of chemotherapeutic agent and their swelling characteristics. Polym. Bullet. 61, 81-90.

Maitra, J. ; Shukla, V.K. (2014). Cross-linking in Hydrogels. Amer. J. Polym. Sci., 4(2), 25-31.

Mallakpour, S.; Ezhieh, A.N. (2017). Preparation and characterization of chitosan-poly (vinyl alcohol) nanocomposite films embedded with functionalized multi-walledcarbon nanotube. Carbohy. Polym., 166, 377-386.

Mallikarjuna, C.; Bhaskar, V.H.; Kumar, J.M.; Mounica, R.; Bolla, S.P. (2014). Review on Hydrogel-A novel carrier. Pharm. Tutor, 2(6), 42-51.

Marin, E.; Rojas, J.; Ciro, Y. (2014). A review of poly vinyl alcohol derivatives: promising materials for pharmceutical and biomedical applications. A.J.P.P., 8(4), 674-684.

Martínez, Y.N.; Cavello, I.; Cavalittob, S.; Illanes, A.; Castro, G.R. (2014). Studies on PVA pectin cryogels containing crosslinked enzyme aggregates of keratinase. Coll. Surf. B. Biointer., 117, 284-289

McKenzie, M.; Betts, D.; Suh, A.; Bui, K.; Kim, L.D. (2015). Hydrogel-Based drug delivery systems for poorly water-soluble drugs. Molecules, 20, 20397-20408.

Mongkolkitikul, S.; Paradee, N.; Sirivat, A. (2018). Electrically controlled release of ibuprofen from conductive poly(3-Methoxydiphen-ylamine)/crosslinked pectin hydrogel. Europ. $J$. Pharm. Sci. 112, 20-27.

Oztop, H. N.; Saraydin, D.; Solpan, D.; Giiven, O. (2003)." Adsorption of BSA onto Radiationcrosslinked Poly ( AAm/HPMA/MA) Terpolymers",Polym. Bull., 50, 183-190.

Parhi, R.(2017)."Cross-linked Hydrogel for Pharmaceutical Applications: A Review" Adv. Pharm. Bull., 7(4), 515-530.

Pourjavadi, A.; Amini- Fazl, M.S.; Ayyari, M. (2007). "Optimization of Synthetic Conditions CMC-g-poly (acrylic acid)/ Celite Composite Superabsorbent by Taguchi Method and determination of its Absorbency Under load" Exp. Poly. let., 1(8), 488-494.

Pourjavadi, A.; Jahromi, P.E.; Seidi, F.; Salimi, H.(2010). "Synthesis and Swelling Behavior of Acrylated Starch-g-Poly(acrylic acid) and Acrylate Starch-g-Poly(acryl amide) Hydrogels"Carbohy. Polym., 79, 933-940. 
Rizwan, M.; Yahya, R.; Hassan, A.; Yar, M.; Azzahari, A.D.; Selvanathan, V.; Sonsudin, F.;Abouloula, C.N. (2017). PH Sensitive Hydrogels in drug delivery: brief history, properties, swelling and release mechanism, material selection and application. Poly., 9, 137-173.

Rose, S. (1989). "Protien Purification Methods a Practical Approach". Harris Elv, Angal S(ed), IRL Press, New York.

Salmawi, K.M. (2007). "Application of poly(vinyl alcohol) (PVA)/Carboxy methyl cellulose $(\mathrm{CMC})$ Hydrogel produced by conventional cross-linking or by freezing and thawing. $J$. Macro. Sci. part A Pure Appl. Chem., 44(6), 619-624.

Saputra, A.H.; Qadhayna, L.; Pitaloka, A.B. (2014). Synthesis and characterization of Carboxymethyl cellulose (CMC) from water hyacinth using ethanol-isobutyl alcohol mixture as the solvents. Int. J. Chem. Eng. Appl., 5(1), 36-40.

Sing, B.; Sharma, D.K.; Gupta, A. (2008). In Vitro release dynamics of thiram fungicide from starch and ploy(methacrylic acid)-based Hydrogeles. J. Haz. Mat., 154, 278-286.

Sriamornsak, P.; Nunthanid, J.; Cheewatanakornkornkool, K.; Manchun, S. (2010). Effect of drug loading method on drug content and drug release from calcium pectinate gel beads. AAPS Pharm. Sci. Tech., 11(3), 1315-1319.

Wang, T.; Gunasekaran, S. (2006). State of water in Chitosan-PVA Hydrogel. J. Appl. Polym. Sci., 101, 3227-3232.

Wang, Y.; He, G.; Li, Z.; Hua, J.; Wu, M.; Gong, J.; Zhang, J.; Ban, L.; Huang, L. (2018). Novel biological hydrogel: swelling behaviors study in salt solutions with different ionic valence number. Polymers, 10, 112-124. 